mit großer Sorgfalt ausgewählt erscheinen. - Ein zweiter Band widmet sich vor allem dem Recht der den Satellitenbetrieb erfassenden internationalen Organisationen, einzelnen Kooperationsprojekten (z.B. Spacelab) und der - spärlichen - nationalen Gesetzgebung.

Die Herausgeber haben ein Loseblattwerk von höchster Benutzerfreundlichkeit vorgelegt, das kein mit dem Weltraumrecht befaßter Praktiker oder Wissenschaftler wird missen mögen.1

Philip Kunig

\title{
New Directions in the Law of the Sea (New Series),
} compiled and edited by Kenneth R. Simmonds

Oceana Publications, Dobbs Ferry, New York, 1983, 4 Bände, Loseblattsammlung, US $\$ 400.00$

Das Ende der 3. UN-Seerechtskonferenz 1982 markiert nicht nur den bisher wichtigsten Versuch zur Schaffung eines einheitlichen internationalen Seerechts, sondern ist zugleich Anlaß für alle Küstenstaaten der Welt, ihre jeweiligen nationalen Seerechte an die neue rechtliche, wirtschaftliche oder umweltpolitische Entwicklung anzupassen. Es gibt also in den letzten Jahren eine wahre Flut von hunderten von nationalen, regionalen und internationalen Regelungen, deren Übersicht auch für Fachleute immer schwerer wird.

Mit der vierbändigen ${ }^{2}$ Loseblattsammlung bietet "New Directions in the Law of the Sea" eine einzigartige Zusammenstellung der Texte der wichtigsten multilateralen und bilateralen Abkommen und der regionalen und nationalen Gesetze, Verordnungen und sonstigen Regelungen zum öffentlichen Seerecht. Die Materialiensammlung enthält ganz überwiegend die Rechtsakte ab 1979 und schließt damit an die elf Bände der gleichnamigen Serie an, die zwischen 1973 und 1982 erschien und gleichfalls bei Oceana erhältlich ist.

Die neue Loseblattsammlung ist systematisch und derzeit in 23 Kapitel untergliedert, innerhalb derer die Materialien fortlaufend numeriert mit Registerzahlen ausgewiesen sind.

Der 1. Band enthält u.a. eine allgemeine Einführung von 64 Seiten zum Internationalen Seerecht in der Fassung des UN-Seerechtsübereinkommens von 1982 sowie aktuelle Tabellen zu den Seerechtsansprüchen aller Staaten. Erfreulich ist die hohe Zahl von 34 nationalen Gesetzen zum jeweiligen Küstenmeer dieser Staaten, während die entsprechenden Quellen zu Wirtschafts- oder Festlandsockelzonen mit 7 bzw. 6 Eintragungen nicht als repräsentativ gelten können, denn es gibt weltweit inzwischen weit über 70 derartige

1 Emeuert sei an dieser Stelle auch der Hinweis auf von Welck/Platzöder, Weltraumrecht/Law of Outer Space, 1987; dazu VRÜ 21 (1988), 122-123.

2 Vgl. zum ersten Band die Rezension von Mahalu in: VRÜ 17 (1984), 545. 
Zonengesetzgebungen. An dieser Stelle fehlt auch ein Abschnitt über Fischereizonen. Hier ist der Leser auf spätere Ergänzungslieferungen angewiesen oder auf repräsentative Fachpublikationen des Seerechtssekretariats der UN.

Der 2. Band ist dagegen eine wahre Fundgrube, denn er enthält über 30 Konventionen und nationale Rechtsakte zum Meeresumweltschutz sowie die wichtigsten Regelungen zum Meeresbergbau, darunter die Registrierungen der Explorationsfelder für Frankreich, Indien, Japan und die UdSSR jeweils mit Kartenskizzen. Andererseits ist bedauerlich, daß das folgende Kapitel Meeresforschung nur zwei Eintragungen (UdSSR und DDR) ausweist, obwohl sehr viel mehr Staaten Gesetzgebungen zur Regelung der Meeresforschung erlassen haben, die bei der Beantragung von Forschungsgenehmigungen eine wachsende Rolle spielen.

Der 3. Band beginnt mit der Streitregelung und einem wichtigen Abschnitt über die Internationale Schiffahrtsorganisation IMO und deren neue Konventionen zur Abwehr von Terrorismus (1988) bzw. zur Bergung von Schiffen im Falle von Havarien (1989). Der Hauptteil mit 16 Quellen ist den Fischereiregelungen gewidmet und dem 3. UN-Seerechtsübereinkommen, das vollständig und mit den wichtigsten Nebenregelungen abgedruckt ist.

Der 4. Band setzt das UN-Seerecht fort, indem die wenig bekannten jährlichen Berichte des UN-Generalsekretärs zum Seerecht abgedruckt sind, die sehr zuverlässig regional und thematisch die Seerechtsentwicklung chronologisch fortschreiben. Es folgt ein Kapitel mit nationalen Erklärungen zur Seerechtspolitik und (wieder vollständig) 15 nationale und mehrseitige Interimsregelungen zum Tiefseebergbau. Am Schluß steht eine 150-seitige Bibliographie und ein Stichwortindex.

Das vorliegende Werk ist naturgemäß auf ständige Ergänzungen ausgelegt, so daß die hier bedauerten Lücken in Form von fehlenden Materialien kein Systemfehler, sondem eher der ungeduldige Wunsch nach Komplettierung des Werkes sind. Die Vielfalt des Quellenmaterials ist beeindruckend und in dieser Mischung von internationalen und nationalen Rechtsakten außerordentlich nützlich für alle Fachleute, die in Wirtschaft, Verwaltung, Forschung und Diplomatie mit dem Seerecht arbeiten. Angesichts der Fülle des zu erfassenden Materials und der geduldigen Mühe der Herausgeber bei der Suche nach schwer zugänglichen Quellen bleiben aus praktischer Sicht nur wenig Anregungen übrig: Man wünscht sich ganz allgemein mehr Karten und zum schnelleren Suchen und Finden Registernummern auf jeder Seite oben (also nicht nur auf der ersten Seite jeder Eintragung).

Der Preis von US $\$ 400.00$ ist angesichts des derzeit im Vergleich zu 1983 niedrigen Dollarkurses inzwischen wohl als angemessen anzusehen.

Uwe Jenisch 